\title{
We are getting there!
}

\section{Lars Engebretsen, 1,2 Kathrin Steffen²}

While finishing our paper on injuries and illnesses during the Olympic Games in Vancouver, we were contemplating our achievements in research on protection of the athlete's health. Granted, 15 years ago, very little had been done except for the occasional epidemiological study, oftentimes with deficient methodology. National and international sports federations were reluctant to even mention injury problems in their sport and not willing to allocate research money. How much this field has changed over the years! The final proof of the merit of this field came with the International Olympic Committee (IOC) President Jacques Rogge's editorial in the British Journal of Sports Medicine 2009, in which he highlighted the new IOC initiatives in the protection of athletes. ${ }^{1}$ The most recent news comes from the American Orthopedic Society for Sports Medicine (AOSSM) and their Stop Sports Injuries campaign. ${ }^{2}$ Their background is the following: injury rates are rising. In a recent report from the Center for Disease Control, high school athletes accounted for an estimated 2 million injuries. More than 5 million sports-related injuries requiring medical treatment occur in children under 18 years old; $50 \%$ of the injuries are due to overuse and are therefore preventable; and the combined healthcare cost in the USA for treatment of youth injuries is more than US $\$ 2.5$ billion.

Both of these initiatives cater for the young athlete, and they both emphasise the importance of increasing physical activity levels of our adolescent population. Whereas the AOSSM campaign targets

${ }^{1}$ IOC Medical Commission, Lausanne, Switzerland ${ }^{2}$ Oslo Sports Trauma Research Center, Department of Sports Medicine, Norwegian School of Sports Sciences, Oslo, Norway

Correspondence to Kathrin Steffen, Oslo Sports Trauma Research Center, Norwegian School of Sports Sciences, PO 4014 Ullevål Stadion, Oslo 0806, Norway; kathrin.steffen@nih.no parents, coaches and healthcare providers, the IOC programme also highlights elite Olympic athletes through their sports medicine professionals, coaches and sport leadership.

So are we ready to go out and prevent these injuries? Even though we have an increasing database on epidemiology of injuries in many sports, data for children and adolescent are still lacking in many sports. ${ }^{3}$ There has been an increase in data for elite, high-level sports through the extensive efforts of FIFA, FINA, FIS, IAAF and IHF, and more recently the IOC, but many sports federations are still lacking epidemiological data on their sports and have no data on the effect of injury prevention strategies. Consequently, there is a need for approaches with solid methodology in many areas. Surveillance systems are necessary, but are not sufficient for prevention. ${ }^{4}$

The next step after injury incidences have been acquired is to study injury risk factors. This issue of BJSM IPHP contains several risk factor studies, all worth your attention. Bjørneboe et al looks at artificial turfs as a risk factor for football injuries (see page 794), and Benneker et al have investigated risk factors for snowboard injuries (see page 816). Risk factor studies are important in the next step in injury prevention when randomised control trials (RCTs) are applied or systematic reviews of RCTs are evaluated such as the paper by Cusimano and Kwok in this issue (see page 781).

There are challenges to the risk factor approach in the elite athlete group. From the IOC's point of view, data on injury risk in the various sports obtained during the Olympic Games are too few to be able to obtain statistically significant evidence on risk factors. The solution to this dilemma may be to pool data from many singlesport championships occurring around the world. But even when we have sufficient epidemiological data and solid data from RCTs on the effect of changing risk factors, we still need to evaluate compliance with injury prevention programmes. Twomey et $a^{5}$ have questioned whether the latest scientific evidence on effective injury prevention is being translated into coaching practices on the football field, and Saunders et al have described the coaches' perspective on implementing an evidence-informed prevention programme in junior community netball. Therefore it warmed the hearts of prevention-geared researchers such as ourselves when we read the article by Soligard et al 'Compliance with an injury prevention programme', the editor's choice in the present issue (see page 787). This paper shows that 'The $11+$ ', a 20 min comprehensive warm-up exercise programme, really works in this setting. This message is encouraging. The paper also illustrates, however, the effort required to obtain good compliance.

We are happy to say that this research field has come far in the last 15 years! Nevertheless, there is a need for more good science in epidemiology, risk factor analysis, and controlled studies on the effect of removing or reducing risk factors. Finally, we need studies on the results of implementing evidence-based prevention programmes.

Competing interests None.

Provenance and peer review Commissioned; not externally peer reviewed.

\section{REFERENCES}

1. Rogge J. An ounce of prevention? Br J Sports Med 2009;43:627.

2. AOSSM. S.T.O.P - Sports Trauma and Overuse Prevention. http://www.aossm.com laccessed 13 July 2010)

3. Steffen K, Engebretsen L. More data needed on injury risk among young elite athletes. Br J Sports Med 2010;44:485-9.

4. Finch C. Surveillance is necessary but not sufficient for prevention. Inj Prev 2008;14:415.

5. Twomey D, Finch C, Roediger E, et al. Preventing lower limb injuries: is the latest evidence being translated into the football field? J Sci Med Sport 2009;12:452-6

6. Saunders N, Otago L, Romiti M, et al. Coaches' perspectives on implementing an evidence-informed injury prevention programme in junior community netball. Br J Sports Med 2010; Published Online First: 11 June 2010 doi:10.1136/ bjsm.2009.069039. 